\title{
A CARTOGRAFIA GEOMORFOLÓGICA DE DETALHE COMO SUBSIDIO AO PLANEJAMENTO TERRITORIAL: O CASO DA BACIA DO RIBEIRÃO ALAM GREI - SP
}

\author{
Patrícia Borges Silveira $^{(\mathrm{a})}$, Cenira Maria Lupinacci $^{(\mathrm{b})}$
}

(a) Doutoranda do Programa de Pós Graduação em Geografia/ UNESP, campus Rio Claro. patygeo@gmail.com

(b) Professora Dra. do Departamento de Planejamento Territorial e Geoprocessamento, UNESP, campus Rio Claro, cenira@rc.unesp.br

\section{EIXO: SISTEMAS GEOMORFOLÓGICOS: ESTRUTURAS, DINÂMICAS E PROCESSOS}

\begin{abstract}
Resumo
A cartografia geomorfológica constitui-se num importante instrumento nas mãos do geógrafo a fim de detectar e prever problemas ambientais, bem como planejar e ordenar o espaço geográfico. Apesar das divergencias referente à elaboraçaõ desse documento, a cartografia geomorfológica tem sido muito utilizada por pesquisadores no mundo todo a fim de compreender as formas de relevo, considerando sua gênese e sua cronologia, o que torna o estudo do mesmo completo e eficiente para planejar e diagnosticar problemas territoriais, frutos das ações humanas ou da própria natureza. Dessa forma, a presente pesquisa construiu e analisou cartas geomorfológicas de detalhe em três periodos distintos, bem como cartas de uso e ocupação da terra dos mesmos períodos na bacia do ribeirão Alam Grei - SP, com o objetivo de demonstrar as alterações no relevo provocados pelas mudanças no uso e ocupação da terra nos anos de 1972, 1995 e 2006.
\end{abstract}

Palavras chave: cartografia geomorfológica, planejamento territorial, bacia hidrográfica.

\section{Introdução}

A cartografia geomorfológica constitui-se num importante intrumento nas mãos do geógrafo a fim de detectar e prever problemas ambientais, bem como planejar e ordenar o espaço geográfico. Cunha e Queiroz (2012) afirmam que, para a realização de um planejamento ambiental adequado e satisfatório, o levantamento e a análise das características do relevo são de suma importancia, já que esse é um dos elementos presentes no substrato físico-natural a ser gerenciado. Assim, para Cunha et al (2003), a geomorfologia tem na cartografia geomorfológica um importante instrumento de comunicação a fim de demonstrar os resultados obtidos na pesquisa.

Segundo Casseti (2005):

“a Cartografia Geomorfológica se constitui em importante instrumento na espacialização dos fatos geomorfológicos, permitindo representar a gênese das formas do relevo e suas relações com a estrutura e processos, bem como com a própria dinâmica dos processos, considerando suas particularidades". (CASSETI, 2005, p.1)

Dessa forma, considera-se que a Geomorfologia é uma ciencia fundamental a fim de promover um planejamento territorial adequado do espaço geográfico, ja que o relevo se constitui como base das ações 
do homem, e que a cartografia geomorfológica é uma grande aliada do pesquisador, já que possibilita a correta representação e leitura da pesquisa realizada desse espaço geográfico.

Contudo, grandes divergencias se fazem presentes entre os pesquisadores ao redor do mundo, principalmene no que diz respeito à padronização da representação cartográfica, que de acordo com Ross (1990) não consegue atender aos diferentes objetivos das pesquisas geomorfológicas. Além disso, como afirmam Cunha e Queiroz (2012):

\begin{abstract}
"convém lembrar que existem dificuldades para a realização dos mapeamentos geomorfológicos que derivam da própria natureza do objeto relevo. Assim, mapear esse objeto, o qual, por definição, é tridimensional, utilizando duas dimensões, cria dificuldades as quais refletem na grande variedade de sugestões, no que se refere aos símbolos e tramas para a realização dessa tarefa.” (CUNHA e QUEIROZ, 2012, p. 1)
\end{abstract}

Outra questão muito abordada é referente a escala do documento cartografico, que irá determinar o conjunto de informações a serem mapeados. De modo geral, as cartas com escala pequena, consideradas como cartas de detalhe, devem apresentar principalmente, de acordo com Tricart (1965), os fenômenos morfoestruturais, enquanto que as cartas de escala grande devem representar fenômenos e formas com algumas dezenas de metros de comprimento. Para a União Geográfica Internacional, considerando as orientações de Tricart (1965), a cartografia de detalhe deve conter dados referentes à morfometria, morfografia, morfogênese e cronologia, o que não se aplica a cartografia de pequena escala. Para Rodrigues e Brito (2000) os mapas geomorfológicos de detalhe se mostram bastante eficazes já que possibilitam "mostrar as formas de relevo mais próximas à percepção visual humana em função de sua escala [ ]" (RODRIGUES E BRITO, 2000, p.1) Já para Florenzano (2008) antes de se escolher a legenda a ser utilizada, bem como o nível de detalhamento, faz-se necessário o levantamento dos dados de sensoriamento remoto e outras fontes disponíveis da área de estudo, assim como a possibilidade da realização de trabalhos de campo e dos objetivos da pesquisa.Apesar das divergencias, a cartografia geomorfológica tem sido muito utilizada por pesquisadores no mundo todo a fim de compreender as formas de relevo, considerando sua gênese e sua cronologia, o que torna o estudo do mesmo completo e eficiente para planejar e diagnosticar problemas territoriais, frutos das ações humanas ou da própria natureza.

Dessa forma, a presente pesquisa construiu e analisou cartas geomorfológicas de detalhe em três periodos distintos, bem como cartas de uso e ocupação da terra dos mesmos períodos na bacia do ribeirão Alam Grei - SP, com o objetivo de demonstrar as alterações no relevo provocados pelas mudanças no uso e ocupação da terra nos anos de 1972, 1995 e 2006.

\title{
2. Área de Estudo
}




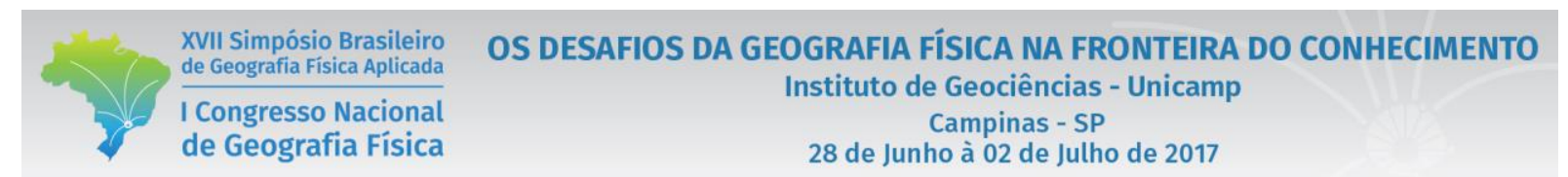

A bacia do ribeirão Alam Grei está localizada no setor norte do município de Rio Claro (SP), sendo o ribeirão Alam Grei afluente direto do rio Corumbataí (fig.1).

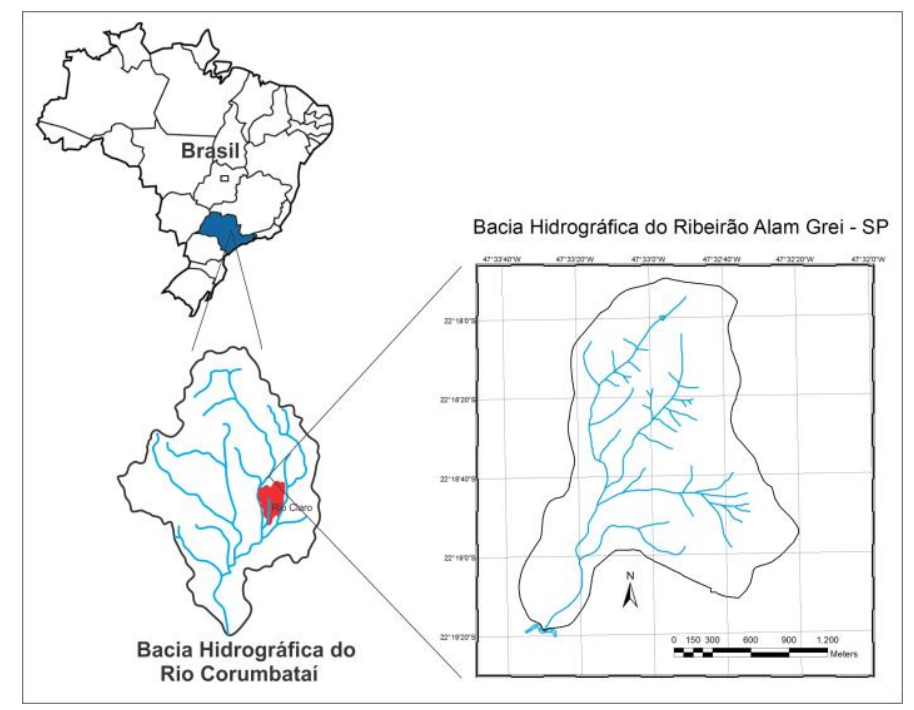

Figura 1 - Localização da área de estudo.

Possuindo uma área de 3,5 $\mathrm{Km}^{2}$, a bacia do ribeirão Alam Grei tem nas atividades agrícolas seu principal uso e ocupação, com excessão do bairro rural que se encontra à leste da mesma. No que se refere à constituição geológica, a referida bacia apresenta como litologias a Formação Corumbataí do Grupo Passa Dois, datada do Paleozóico - Permiano Superior e a Formação Rio Claro, inserida no contexto dos depósitos Cenozóicos da Depressão Periférica (IPT, 1981).

Sobre tais Formações, segundo IAC (1989) e Koffler (1992), ocorrem as seguintes classes de solos: Latossolo Vermelho-Amarelo, Álico - A moderado, textura média, Unidade Coqueiro; Argissolo Vermelho-Amarelo, Tb abrupto, A moderado, textura arenosa/argilosa ou média/argilosa, Unidade Santa Cruz; Neossolo Litólico, A moderado, proeminente ou chernozêmico, substrato sedimentos indiscriminados do Grupo Passa Dois; e Gleissolos, Glei Húmico e Glei Pouco Húmico com ou sem Solo Orgânico.

Segundo a classificação de Koppen (citado por Silva e Pfeifer, 1998, p.11), o clima da região é o mesotérmico úmido subtropical de inverno seco (Cwa), caracterizado por apresentar temperaturas mais elevadas no mês de janeiro, com média de $25,1^{\circ} \mathrm{C}$ e temperaturas mais amenas no mês de julho com uma média de $17,5^{\circ} \mathrm{C}$. Assim, fica evidente por esta caracterização da área que o substrato físico apresenta algumas fragilidades, o que pode ser observado, por exemplo, pela presença de solos do tipo Argissolos e Neossolos, os quais são potencialmente suscetíveis aos processos erosivos. 


\section{Procedimentos Técnicos Cartográficos}

A fim de alcançar os objetivos estabelecidos para a presente pesquisa foram construídas três cartas geomorfológicas referentes ao ano de 1972, 1995 e 2006, bem como três cartas de uso e ocupação da terra referentes aos mesmos períodos. Além dessas, foi construída uma carta de declividade do relevo, a fim de representar a morfometria do terreno.

\section{1 - As Cartas Geomorfológicas}

Para a elaboração das cartas geomorfológicas foram seguidas as orientações de Tricart (1965) com algumas adaptações. Para esse autor as cartas geomorfológicas devem contemplar informações morfométricas, morfográficas, morfogenéticas e dados cronológicos do relevo. Para a representação dos dados morfométricos, a fim de não poluir as cartas geomorfológicas com muitas informações, optou-se pela construção de uma carta de declividade à parte, a fim de que a leitura dos documentos cartográficos seja clara e precisa.

Quanto à morfografia, esta foi obtida pela interpretação de pares esteroscópicos de fotografias aereas. Para o ano de 1972 foram utilizadas fotografias aereas com escala aproximada de 1:30.000, para o ano de 1995 as fotografias aereas disponíveis foram na escala aproximada de 1:5.000, e de 1:25.000 no ano de 2006. De acordo com Cunha et al (2003), os dados referentes à morfografia devem ser representados por "simbolos que localizam e espacializam as formas de relevo, representando a extensão destas" (CUNHA et al, 2003, p. 3). Segundo Casseti (2005) a morfografia do relevo está intimamente ligada a sua morfogênese, ou seja, as formas estão relacionadas às suas respectivas gênesis.

Dessa forma, a morfogênese foi representada pelo agrupamento dos símbolos morfográficos, sendo que, de acordo com Cunha et al (2003):

os símbolos que representam as formas devem trazer embutidos sua origem e gênese, a fim de tornar distinguíveis os processos morfogenéticos atuantes na área. (CUNHA et al, 2003, p. 3)

Já a cronologia foi abordada somente em termos relativos por níveis altimétricos e por dados de geologia de superfície disponíveis, devido essa informação ser a mais complexa de se obter.

\section{2 - A Carta de Declividade do Relevo}

A técnica de construção da carta clinográfica da bacia hidrográfica do Ribeirão Alam Grei seguiu a proposta desenvolvida por De Biasi (1970), que tem como base a compreensão das cartas topográficas, 


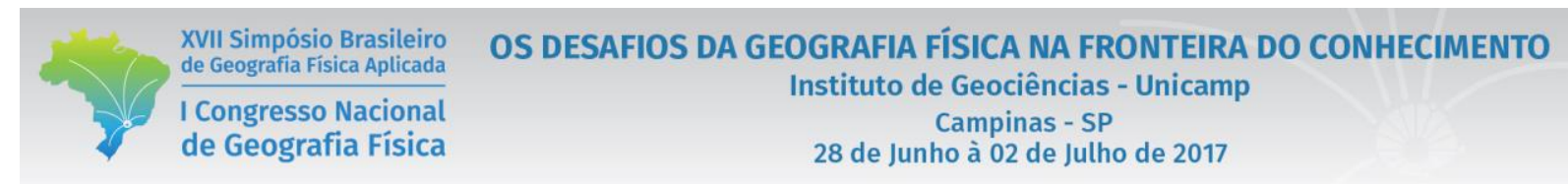

nas quais se observa que quanto mais próximas estiverem as curvas de nível, maior será a declividade do terreno e quanto mais distantes, menor será a declividade. As curvas de nível, bem como os dados da rede de drenagem, fundamentais para a construção desse documento cartográfico, foram compilados da Carta Topográfica de Rio Claro Folha - Granja Ipê - SF.23-Y-A-I-4-NE-D, escala 1:10.000, CESP, editada em 1978

As classes de declividade podem ser determinadas pelo pesquisador de acordo com os seus objetivos. Para a presente pesquisa as classes de declividade escolhidas foram (tabela 1):

Tabela 1 - Classes de declividade utilizadas na presente pesquisa.

\begin{tabular}{|c|c|}
\hline Classes: & Justificativa: \\
\hline$<3 \%$ & Áreas consideradas susceptíveis à inundação. \\
\hline $3-6 \%$ & Áreas possíveis de urbanização sem risco de inundação. \\
\hline $6+12 \%$ & $\begin{array}{l}\text { Terrenos onde é possível tanto a urbanização, como a mecanização } \\
\text { agrícola. }\end{array}$ \\
\hline $12-20 \%$ & Restrições à mecanização agrícola. \\
\hline $20 \vdash 30 \%$ & Declividade máxima onde é permitida a urbanização. \\
\hline$\geq 30 \%$ & Restrições à urbanização. \\
\hline
\end{tabular}

\section{3 - As Cartas de Uso e Ocupação da Terra}

As cartas de Uso e Ocupação da Terra foram elaboradas por meio da fotointerpretação de pares estereoscópicos das mesmas fotografias aéreas utilizadas para o mapeamento geomorfológico. Para a identificação das classes de uso e ocupação da terra foram utilizados os elementos apontados por Ceron e Diniz (1996) como essenciais para a identificação das culturas, a saber: a tonalidade, textura, forma da parcela, dimensão da área cultivada, altura, espaçamento, restos de colheita e arranjo espacial. Além disso, de acordo com o IBGE (2006):

Dados de sensoriamento remoto, [ ] podem ser correlacionados com a cobertura da terra e usados para mapear o tema. Entretanto, como o sensor remoto não registra a atividade diretamente, mas características da superfície da terra que retratam o revestimento do solo, as atividades de uso da terra correlacionadas à cobertura, precisam ser interpretadas a partir de modelos, tonalidades, texturas, formas, arranjos espaciais das atividades e localização no terreno. (IBGE, 2006, p. 40)

Dessa forma, as classes mapeadas na bacia do ribeirão Alam Grei foram: área urbana, área construída (diz respeito a locais que possuem construções isoladas), mata, pastagem, pasto sujo (são as áreas de pastagem 
que apresentam vegetação arbustiva distribuída pela área), cana-de-açúcar, silvicultura, cultura anual e cultura temporária.

\section{Análise dos Resultados e Discussões}

A fim de facilitar a análise dos resultados, os dados serão apresentados por setores da bacia do ribeirão Alam Grei, de acordo com as mudanças mais significativas apresentadas pelas cartas.

No setor nordeste da bacia (fig. 2) é possível observar que no ano de 1972 a forma mapeada na alta vertente era predominantemente a côncava, seguida por uma ruptura topográfica bastante expressiva que se estendia em toda média vertente desse setor. $\mathrm{Na}$ média vertente, as formas variavam, predominantemente, entre convexa e côncava. Além disso, é possível observar uma ruptura topográfica de menor extensão já na baixa vertente, próxima ao curso d'água e apenas uma feição erosiva de sulco. $\mathrm{O}$ setor nordeste da bacia possui as seguintes classes de declividade que se dividem em, de 0 - $6 \%$ nos topos, de $6-20 \%$ na média vertente e declividades mais acentuadas na baixa vertente, variando de $20 \%$ a $\geq 30 \%$. Sobre essas formas do relevo havia, em 1972, predominantemente, a ocupação de pastagens e pasto sujo. Já no ano de 1995, esse setor apresenta vertentes bastante alteradas, se comparadas ao cenário de 1972. Primeiramente é possível observar rupturas topográficas de menor extensão territorial, porém em maior número distribuídas pelas médias e baixas vertentes. As rupturas topográficas são feições denudativas que indicam a dinâmica das vertentes, já que demonstram um processo erosivo diferenciado ao longo das mesmas que pode ser explicado pelos diferentes materiais que compõem a litologia. Porém, as ações humanas de uso e ocupação da terra, podem dinamizar esse processo, quando não respeitadas as características fisicas e naturais do terreno. Assim, as rupturas topográficas presentes no setor nordeste da bacia podem estar associadas às mudanças no uso e ocupação da terra, que em 1995 passou a contar com áreas destinadas à silvicutura, culturas anuais e perenes, além de áreas de pastagens. 


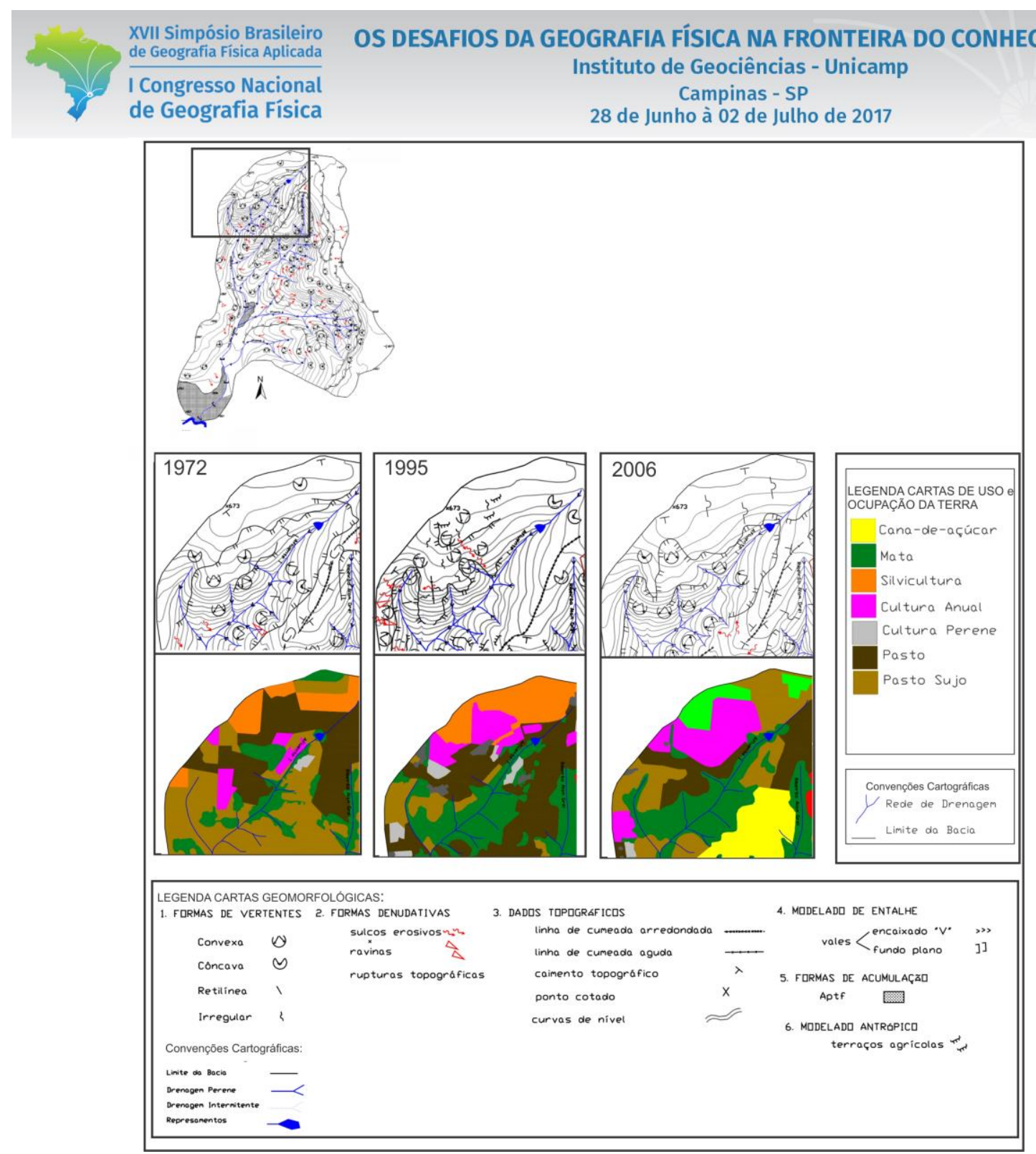

Figura 2 - Recortes das cartas geomorfológicas e de uso e ocupação da terra do setor nordeste da bacia do ribeirão Alam Grei.

Além disso, formas denudativas vinculadas a sulcos erosivos e ravinas aparecem de forma bastante expressiva em todo o setor, sendo mapeados nove sulcos erosivos e duas ravinas. Constata-se também uma alteração no formato das vertentes, com predominio das formas irregulares. Tais alterações do terreno indicam que o uso e ocupação da terra não respeitava as características e fragilidades do substrato físico da área.

No ano de 2006, o cenário nesse setor se altera novamente, principalmente no que se diz respeito às rupturas topográficas. Novamente, tem-se a presença de uma ruptura bastante acentuada que se prolonga por todo o setor nordeste. Contudo, as feiçoes erosivas desaparecem, bem como os terraços agrícolas, que eram presentes no cenário anterior. Novamente, as classes de uso e ocupação da terra passaram por uma 


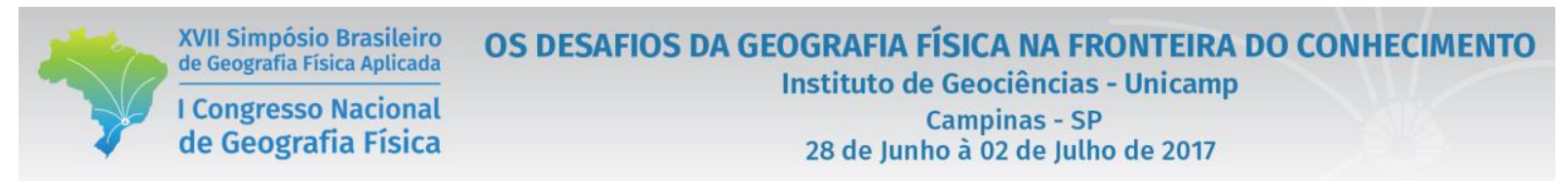

alteração: as áreas de cultura perene aumentaram, as culturas anuais desapareceram e as áreas de pastagens continuam presentes no setor. Porém, a mudança mais significativa, que justifica a ausência das formas erosivas, foi o aumento da área de mata em todo setor nordeste.

Outro setor que merece destaque é o interflúvio entre o ribeirão Alam Grei e seu principal afluente, aqui denominado de afluente 1 (fig.3). Tal área apresenta classes de declividade predominates de $20 \vdash 30 \%$ e $\geq 30 \%$, presente nas médias e baixas vertentes, seguida pela classe de $12-20 \%$.

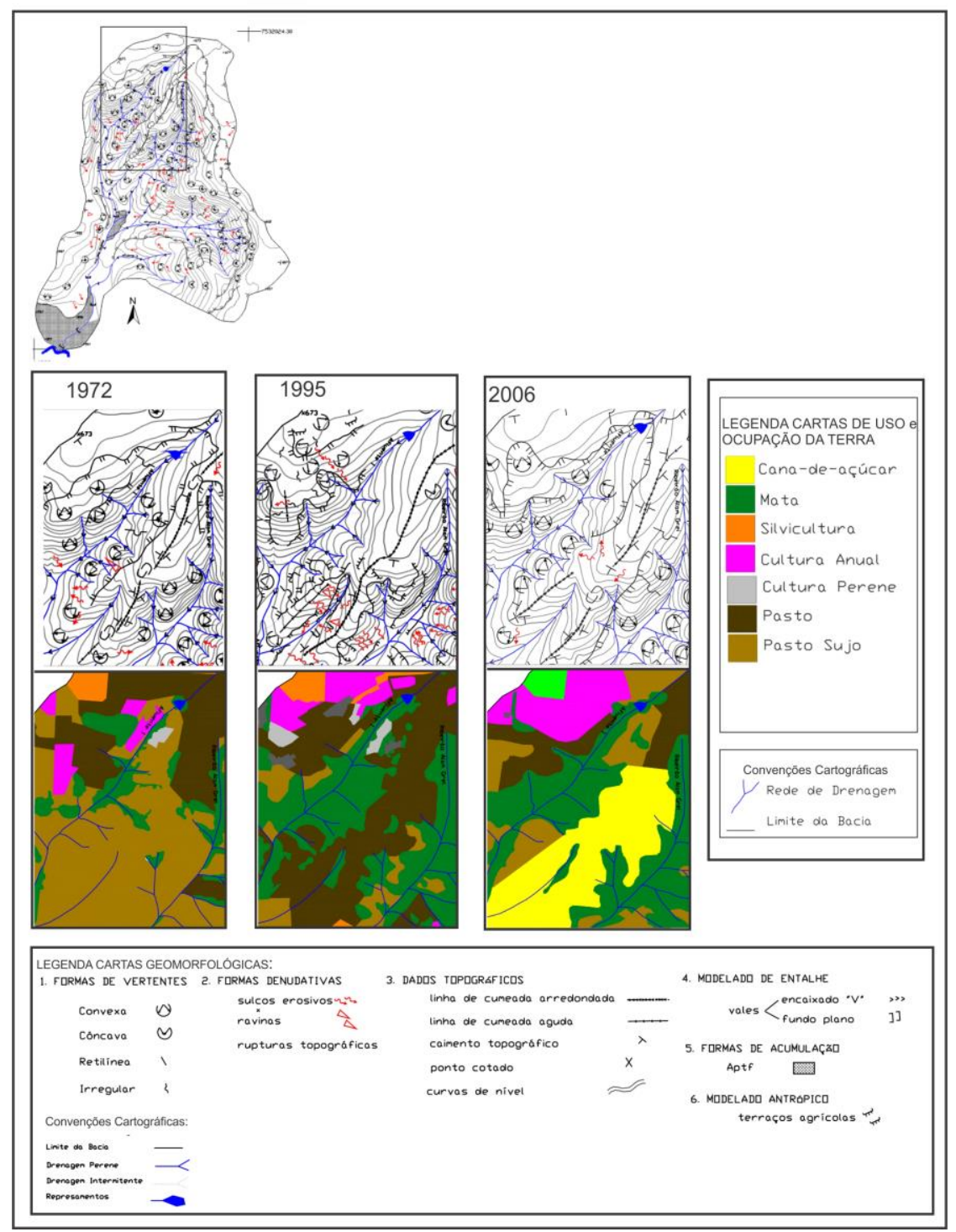

Figura 3 - Recortes das cartas geomorfológicas e de uso e ocupação da terra do interflúvio entre o ribeirão Alam Grei e o afluente 1.

Em 1972 esse setor possuia linhas de cumeadas com feições arredondadas e agudas, separadas por colos recobertos pelo uso da terra destinado predominantemente ao pasto sujo. Ao se analisar esse mesmo 
interflúvio no ano de 1995, verifica-se a ausência dos e a presença de uma linha de cumeada que se torna contínua e totalmente arredondada. Nesse ano, a classe de uso e ocupação da terra passa a ser, predominantemente, os pastos limpos cujo manejo possivelmente mascara os colos. No ano de 2006 porém, a linha de cumeada volta a ser descontínua e, novamente têm-se a presença de um colo separando tais linhas, que passam a ser bastante agudas, tornando-se mais arredondadas nas áreas nas quais a declividade do terreno é menos acentuada. No ano de 2006 essa área era destinada ao cultivo de cana-deaçúcar, com excessão apenas nas áreas de mata ciliar.

Além disso, podemos destacar também as formas denudativas que, em 1972, apresentavam-se somente na vertente oeste, em direção ao ribeirão Alam Grei. Tais feições se caracterizavam por uma ruptura topográfica bastante extensa na média vertente e algumas feições erosivas, a saber, três sulcos erosivos e uma ravina. Contudo, no ano de 1995, as rupturas topográficas aparecem em maior quantidade, tanto na vertente oeste como na vertente leste desse interflúvio, e as feições erosivas aparecem em maior número, sendo onze sulcos erosivos e duas ravinas. Tal fato demonstra um desequilíbrio dessas vertentes devido às alterações no uso e ocupação da terra. Já em 2006, as rupturas topográficas diminuem em extensão e quantidade, como também as feições erosivas que agora somam apenas três sulcos erosivos. Tal fato pode ser explicado pelo preparo da terra para o cultivo da cana-de-açúcar, onde as feições erosivas foram mascaradas e as rupturas topográficas alteradas.

Outra área bastante alterada se encontra no setor oeste da bacia, próximo ao baixo curso do ribeirão Alam Grei (figura 4). No primeiro ano analisado, 1972, tal área era destinada ao uso de pastos sujos, predominantemente, e as feições erosivas mapeadas somavam três sulcos e uma ravina. Além disso, apenas uma ruptura topográfica, de média extensão territorial, foi registrada na baixa vertente. Quanto às vertentes, essas possuíam formas côncavas e convexas. Nesse setor, constata-se também que o fundo de vale torna-se plano, diferentemente dos setores analisados anteriormente que apresentavam vales encaixados.

Em 1995, ocorre uma mudança bastante intensa nesse setor no que diz respeito às formas denudativas, bem como nas formas das vertentes. Em relação às formas denudativas foram mapeados quatorze sulcos erosivos e uma ravina; além disso, as rupturas topográficas se tornam numerosas, sendo seis delas de menor extensão e duas de grande extensão territorial. Quanto as formas das vertentes, essas passam a ter formas irregulares, além das côncavas e convexas. Também foi possível mapear nesse setor os terraços agrícolas, frutos do cultivo da cana-de-açúcar que em 1995 ocupava predominantemente a área. Assim, fica evidente também nesse setor um provável desequilíbrio dessas vertentes devido a um uso e ocupação da terra que não se era praticado com o devido manejo agrícola, a fim de diminuir os impactos da agrricultura no terreno. 


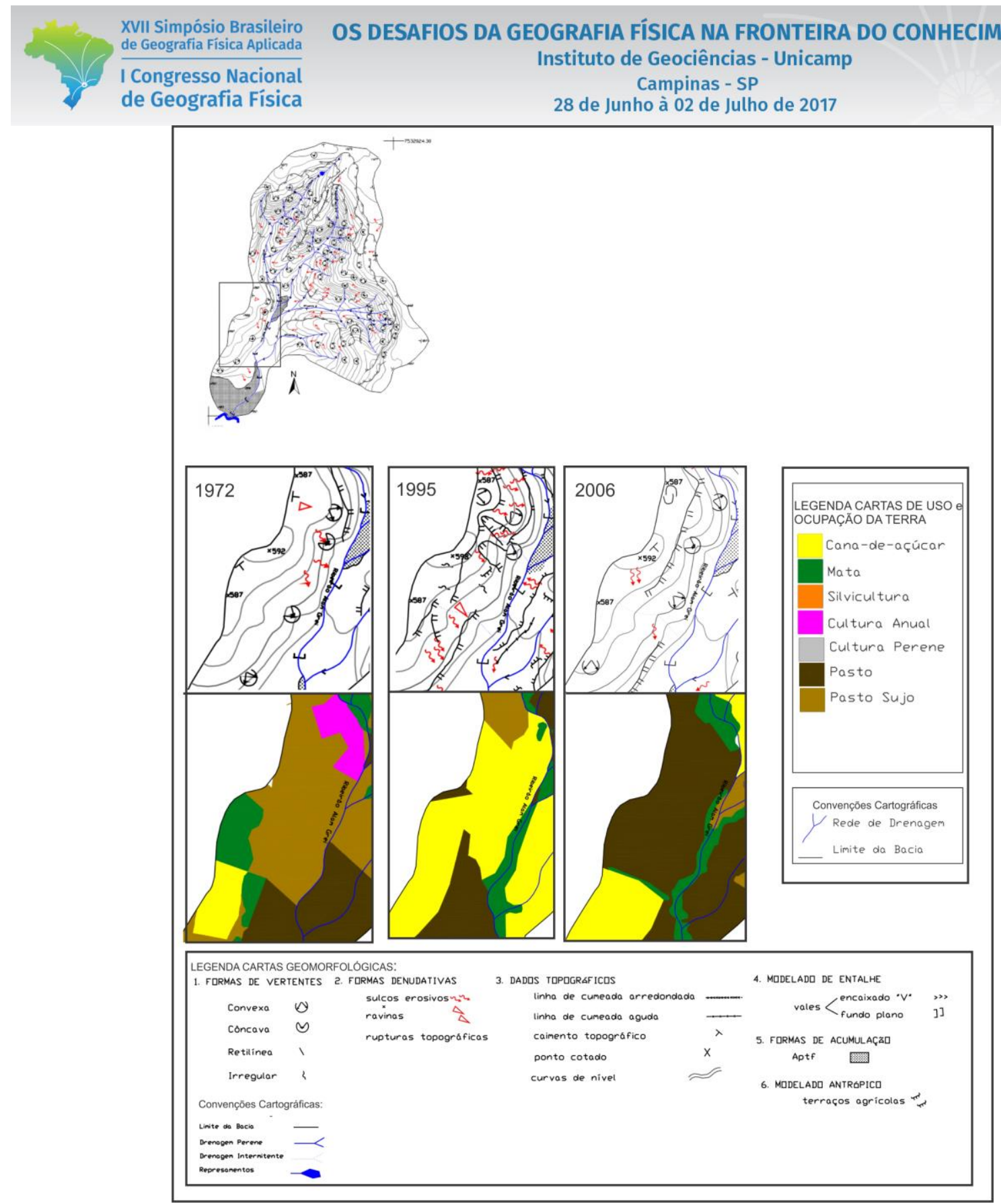

Figura 4 - Recortes das cartas geomorfológicas e de uso e ocupação da terra do oeste da bacia do ribeirão Alam Grei.

Por fim, no ano de 2006, as áreas de pastagens passam a predominar nessa área, alterando novamente as características do relevo: as vertentes passam a ter formas convexas, predominantemente, e côncavas. As rupturas topográficas diminuem, assim como as feições erosivas, que agora são representadas por três sulcos erosivos. Quanto à declividade, predomina nesse setor a classe de 6 - $12 \%$. 


\section{Considerações Finais}

Com base nos resultados obtidos pode-se afirmar que as práticas agrícolas podem interferir significativamente nas características do relevo quando a mesma ocorre sem o devido planejamento e manejo adequado, de maneira a preservar as características físicas do mesmo. Tal fato fica comprovado nos setores analisados, quando se constata o crescimento ou diminuição das feições denudativas, aqui representadas pelas rupturas topográficas e feições erosivas de sulcos e ravinas, que se alteram conforme as mudanças de uso e ocupação da terra, bem como as alterações na morfologia das vertentes que também se comporta de acordo com esses usos.

Assim, considera-se que as técnicas cartográficas empregadas se mostraram satisfatórias para a construção dos mapas temáticos de uso e ocupação da terra e das cartas geomorfológicas, a fim de alcançar o objetivo proposto a essa pesquisa. Destaca-se a cartografia geomorfológica que se demonstrou eficaz ao espacializar as formas denudativas e demonstrar as alterações nas formas de vertentes e linhas de cumeadas, indicando assim um possível desequilíbrio das áreas de acordo com o uso e ocupação da terra.

Tais dados demonstram a necessidade do planejamento territorial da área, a fim de amenizar os impactos negativos das práticas agrícolas.

\section{Bibliografia}

CASSETI, V. Cartografia Geomorfológica, 2005. Livro Digital. Disponível em: http://www.funape.org.br/geomorfologia/. Acesso em: 02/02/2017.

CERON, A.O.; DINIZ, J.A.F. O Uso de Fotografias Aéreas na Identificação das Formas de Utilização Agrícola da Terra. Revista Brasileira de Geografia. Rio de Janeiro, no .2, p. 161-172, 1996.

CUNHA, C.L. et al. A Cartografia do Relevo: Uma Análise Comparativa de Técnicas para a Gestão Ambiental. Revista Brasileira de Geomorfologia. Ano 4, nº.1, p. 1 - 9, 2003.

CUNHA, C.L. QUEIROZ, D.S. A Cartografia Geomorfológica de Detalhe: Uma Proposta visando a Multidisciplinaridade. Revista CLIMEP. Rio Claro, vol. 7, nº 1-2, p. 22, 2012.

DE BIASI, M. Cartas de Declividade: Confecção e Utilização. Geomorfologia, São Paulo, n.21, p. 8-12, 1970.

FLORENZANO, T. G (Org). Geomorfologia: Conceitos e tecnologias atuais. São Paulo: Oficina de Textos, 2008, $318 \mathrm{p}$.

KOFFLER, N.F. Solos da Bacia do Rio Corumbataí. Universidade Estadual Paulista - IGCE - Departamento de Cartografia e Análise da Informação Geográfica, campus Rio Claro, SP, escala 1:50.000, 1992.

IAC, InStuto AgronÔMICO DE CAMPINAS. Carta Pedológica Semi-Detalha do Estado de São Paulo: Folha de São Carlos (SF.23-Y-A-IV), escala 1:100.000, 1989. 
IAC, INSTITUTO AGRONÔMICO DE CAMPINAS. Levantamento Pedológico Semidetalhado do Estado de São Paulo: Quadrícula São Carlos II. Memorial Descritivo. Campinas, 1984.

IPT, INSTITUTO DE PESQUISA TÉCNOLÓGICA. Mapa Geológico do Estado de São Paulo. São Paulo: IPT, $1981 \mathrm{~b}$

IBGE. Manual técnico de uso da terra. Rio de janeiro: Ministério do Planejamento; Orçamento e Gestão; Instituto Brasileiro de Geografia e Estatística - IBGE; Diretoria de Geociências; Coordenação de Recursos Naturais e Estudos Ambientais, 2. ed., 2006, 91 p.

RODRIGUES, S.C. BRITO, J.L.S. Mapeamento Geomorfológico de Detalhe - Uma Proposta de Associação entre o Mapeamento Tradicional e as Novas Técnicas em Geoprocessamento. Caminhos de Geografia. Uberlândia, 1 (1), p. $1-6,2000$.

ROSS, J. L. S. Geomorfologia: ambiente e planejamento. São Paulo: Contexto, 1990. 85p.

SILVA, D.A.; PFEIFER, R.M. Zoneamento de Uso das Terras da Estação Experimental de Tupi-SP. Revista do Instituto Florestal, São Paulo, v.10, n. 1, p. 23-38, 1998.

TRICART, J. Principes et Méthodes de la Géomorphologie. Paris: Masson et Cie, 1965. 